\title{
ARTICLE
}

\section{Mental health in children with severe hearing impairment}

\author{
Nicoletta Gentili \& Andrew Holwell
}

Nicoletta Gentili is a consultant child psychiatrist in south-west London. She leads the only in-patient unit for deaf children and young people in the UK and mainland Europe. She is also an honorary senior lecturer in South West London and St George's NHS Trust. Her research interests lie in the field of emotions and developmental psychology.

Andrew Holwell is a consultant child and adolescent psychiatrist who has worked in the field of deafness and mental health for the past 5 years, having a special interest in autism-spectrum disorders. He is part of the London team of the National Commissioning Group's Deaf Children, Young People and Family Service.

Correspondence Dr Nicoletta Gentili, Corner House Inpatient Unit, Building 16, Springfield University Hospital, 61 Glenburnie Road, London SW17 7DJ, UK. Email: nicoletta.gentili@swlstg-tr.nhs.uk

\begin{abstract}
SUMMARY
Deafness does not in itself cause emotional/ behavioural or cognitive problems or psychiatric disorders. However, children with hearing impairment are at greater risk of developing emotional/ behavioural problems and neurodevelopmental disorders. The incidence of both seems to be higher in deaf children from hearing families. Most prelingual deafness is caused by recessive genes; hence, most deaf individuals come from hearing families, the majority of whom do not use sign language. Numerous studies, in both hearing and deaf populations, show how the lack of access to language has an impact on the emotional development of children. This article focuses on the mechanisms by which early language deprivation mediates emotional/behavioural difficulties and consequent emotional dysregulation, and may produce behaviours and symptoms that can be misdiagnosed as neurodevelopmental disorders in deaf children and adolescents (from infancy to 18 years of age).

\section{DECLARATION OF INTEREST}

None.
\end{abstract}

Hearing impairment from birth or early infancy may have lifelong consequences for an individual's social adjustment and mental well-being in terms of communication, education, identity and employment (Hauser 2006; Woll 2008). A number of comorbid conditions that often accompany this sensory impairment might contribute to the development of mental disorders encountered in deaf children (Roberts 1999). Specific environmental factors, including familial, social, cultural and educational influences, can be both the direct and the indirect basis for the development of emotional/behavioural problems and psychiatric disorders through a diversion of the child's developmental pathway. Lack of effective communication with carers, typically in families with hearing parents and deaf children, and consequent lack of or delayed language development is one of the most important environmental aetiological factors, albeit not the only one. Language deprivation has an impact on the quality of the shared emotional environment with the carer and potentially on the attachment relationship. It may also affect the individual's cognitive ability and executive functions (Hauser 2006) and their ability to understand and share the emotional states of others and develop friendships (Dunn 2004). In this article, using the body of knowledge and research carried out on brain development, language and intersubjectivity, we focus on two aspects of mental health problems in individuals between infancy and 18 years of age with severe hearing impairment (whom we refer to here as deaf children, for conciseness): the intricate mechanisms that could be the foundation of the development of emotional/behavioural problems and how early language deprivation can cause symptoms that mimic attention-deficit hyperactivity disorder (ADHD) and autismspectrum disorders.

\section{Epidemiology of psychiatric disorders and communication}

The total number of deaf children aged $0-15$ years in the UK is around 20000 (Woll2008), and around $95 \%$ of them will have been born to hearing parents (Mitchell 2004). In sensorineural deafness (Box 1), at least $50 \%$ of cases have a genetic aetiology (Steel 1999); non-hereditary causes of sensorineural hearing loss include: congenital infections such as cytomegalovirus and rubella, perinatal anoxia and postnatal infections such as bacterial meningitis. Complications as a result of premature birth can also result in deafness (Wills 2005). These nonhereditary forms of deafness are often associated

BOX 1 The two main types of hearing loss

Conductive

- Involves the middle/outer ear

- Rarely causes severe to profound hearing loss

- The main cause is otitis media with effusion

Sensorineural

- Involves the inner ear, most frequently the cochlea, with damage to Corti's organ or to the auditory nervous system

- Has a genetic cause in at least $50 \%$ of cases

- In most cases the gene is recessive 
with other neurological sequelae that may affect behavioural, emotional and cognitive functioning (Hauser 2006).

Beforethemid-1990s, the prevalence of psychiatric disorders in deaf children and adolescents was unclear. This was largely because the assessment instruments used had not been validated in the deaf population and the children themselves were rarely interviewed (Hindley 1997). A pilot study of new psychiatric screening questionnaires designed for this age group suggested that about $50 \%$ would have a mental health problem at some time before adulthood (Hindley 1994). Many subsequent studies (e.g. Hindley 1997; Van Eldik 2004) show a higher incidence and prevalence of mental health problems in deaf children compared with their hearing counterparts. Specifically, emotional and behavioural problems seem to be twice as common among deaf children (Vostanis 1997). Neurodevelopmental disorders appear to have a different prevalence: the incidence of ADHD in children with inherited deafness is the same as in their hearing counterparts but higher than in children with non-inherited deafness (Hindley 1998). This might be because medical conditions such as cytomegalovirus and rubella can cause both deafness and ADHD (Hindley 2005). Studies in the hearing population estimate the prevalence of autism-spectrum disorders to be between 58 and 67 per 10000 (Tidmarsh 2003).

An association between a number of causes of deafness (such as CHARGE syndrome, rubella, cytomegalovirus and autism) has been observed (Jure 1991). Studies have found that the incidence of deafness is increased among children with autism-spectrum disorders (Rosenhall 1999). Conversely, the albeit limited research indicates that the incidence of autism-spectrum disorders among deaf students is also significantly higher, with one study identifying an estimated incidence of 1 in 76 (Gallaudet Research Institute 2007) and another of 4\% (Jure 1991).

Deaf children are at greater risk of being physically and sexually abused than the hearing population (Sullivan 1991) and this in itself could trigger the development of emotional/behavioural problems or other psychiatric disorders (MacMillan 2001). Studies involving hearing children have shown how the emotional experience of physical abuse has an impact on their attentional abilities (Pollak 2003).

It has been estimated that $90 \%$ of deaf children who experience mental health problems come from hearing families (Moores 1987). Often these families have difficulties accepting deafness and in turn learning to use an adequate level of communication with their child (du Feu 2003).
It should be noted that when many of these studies were carried out, the average age at which deafness was diagnosed among children in the UK was around 20 months, and families were therefore unaware of their child's needs for a crucial period of his or her development. Consequently, the incidence of early language deprivation was potentially higher. Medical advances and improvements in technology implemented in the mid-2000s have reduced the average age of diagnosis in the UK to under 3 months (Woll 2008).

\section{The value of early intervention}

A study in Finland found that the incidence of mental health problems among deaf children of parents who learnt to communicate adequately with them from infancy was much the same as among hearing children: 18.75 v. $15.8 \%$ (Sinkkonen 1994). Interestingly, all the hearing mothers of the children in this study and 94\% of the hearing fathers had sign language skills and this was the preferred mode of communication in all the families sampled. This suggests that deaf children who grow up in psychologically healthy families in which they are not abused and with parents who have learnt to sign fluently will have the same incidence of mental health problems as their hearing peers. Other studies have shown that families who are helped to learn sign language can establish a more effective way of communicating with their children, thus improving their social and emotional development (Vaccari 1997).

There is some evidence that if early diagnosis is accompanied by intervention and support before the baby reaches 6 months of age, parental adjustment is better and the child's language development is improved (Yoshinaga-Itano 2000).

These findings suggest that deafness is not in itself the direct cause of developmental, emotional/ behavioural and cognitive problems or psychiatric disorders and that it is extremely important for parents to learn how to communicate effectively with their deaf child from a very early age.

\section{Language and emotion}

As discussed above, it is clear that deaf children from hearing families where there is not an adequate level of communication have a higher incidence of mental health problems than their hearing counterparts. This often seems to be related to a lack of language development caused by either a delayed diagnosis of deafness and/or families failing or being unable to learn how to communicate effectively with their deaf child. This language deficit will have an impact on the essential development, understanding and regulation of 
emotions. This developmental process is generally thought to occur through language acquisition, the close link between language and executive functions, and the intersubjective relationship between the parents and the child, within which attachment and the pattern of emotions develop (Box 2).

Language in humans is uniquely complex. All species are able to communicate, but humans have the ability to discuss objects even in their absence, even when they are temporally distant. Human communication implies time and space. It is through the use of language that we can pass our experience on to others, enabling the process of learning to be more efficient and less dangerous. Language also enables the identification and labelling of emotions, which allows individuals to develop the ability to decode their own emotional states and achieve better emotional regulation. Language enables the disambiguation of unclear situations and allows a greater abstraction of thinking through the articulation of past experience and future goals. Studies on the interaction between language and emotions highlight how the labelling of emotions increases activity in the inferior frontal gyrus and decreases the amygdala response (Box 3) (Lieberman 2007). Research illustrates that children from families in which feelings are discussed with them are especially successful in performing on tests of social understanding (Meins 1999). In essence, language is the fundamental instrument of emotional regulation, as well as having a critical impact on executive functions,

B0X 2 Intersubjectivity

- Intersubjectivity has been described as the sharing of subjective states by two or more individuals (Scheff 2006).

- The experience of one's subjectivity must contain the anticipation of the other: if I observe myself while I am doing something, I am anticipating what I would see in others if they did it or what others would see while observing me (MerleauPonty 1945)

- Between 2 and 12 months of age, babies become capable of grasping other people's intentions (Tomasello 1999). This occurs through shared attention, the ability to follow the other's gaze, pointing and imitational learning.

- By 4 or 5 years of age, children are able to understand others as 'mental agents' with different beliefs from themselves.
BOX 3 Affect labelling and the amygdala response

- The amygdala is the key player in an extensive neural network involved in the processing of fear and other basic emotions. It appears to play an important role in five major areas (LeDoux 2005):

implicit emotional learning and memory

emotional modulation of memory

emotional influences on attention and perception emotion and social behaviour emotion inhibition and regulation.

- A relationship between the prefrontal cortex and amygdala has been identified in fear extinction: neural activity in the ventromedial prefrontal cortex increases as extinction is learnt (Milad 2002; Rosenkranz 2003).

- Putting feelings into words may alleviate negative emotional response: studies on 'affect labelling' show that linguistic processing of the emotional aspect of an emotional image produces reduced amygdala activity compared with the perceptual processing of the emotional aspect of the same image (Lieberman 2005).

- These studies have also demonstrated greater activity in the right ventrolateral prefrontal cortex (RVLPFC) during linguistic processing. This region is associated with the symbolic processing of emotional information (Nomura 2003). Owing to the inverse correlation of the activity of the RVLPFC and the amygdala during affect labelling, it might be suggested that putting feelings into words may activate the RVLPFC, which in turn reduces the amygdala response and, thus, the emotional distress.

cognition and the ability to understand the emotional states and viewpoints of others.

An average child has the potential to learn 10000-15000 words between 18 months and 5 five years of age. This rapid learning is the result of an in-built tendency to communicate and imitate (Tomasello 2000). These imitational abilities have been demonstrated by a large body of research and are supported by the discovery of the "mirror neuron system' (Box 4) (Rizzolatti 1996). By the time children utter their first lexicogrammatical speech (words used within grammatical parameters) they have begun to master grammar, to use words to refer to and mean things, and have learnt how to realise their intentions communicatively (Bruner 1983).

Vygotsky (1978), Bruner (1983) and Tomasello (2008) highlight the importance of a shared human interest in the process of learning, over and above our natural tendency to learn. Bruner (1983) calls this social support to the process of acquiring language the 'language acquisition support system' 
BOX 4 Mirror neurons

Mirror neurons fire both when a goal-directed action is carried out and when an observer watches the same action carried out by another. This phenomenon seems to be related to the meaning of the action itself (Rizzolatti 2004). Mirror neurons underpin the ability to understand and recognise others' actions, and also the intentions that promoted them (Rizzolatti 2006).

These neurons have been found in the premotor cortex, supplementary motor area, primary somatosensory cortex and inferior parietal cortex. The last region is involved in language production, hence the theorised implication of these neurons in communication.

Owing to their strong implication in understanding the actions/emotions and intentions of others, mirror neurons have also been studied in relation to autism (Dapretto 2006).

(LASS). This theory is supported by a body of research showing how children's grammatical skills tend to be varied over the first 2.5 years of life and links this finding to environmental factors as well as innate ones. Some studies (Nelson 1977) have found that providing children with extra examples of complex syntactical constructions facilitates the acquisition of such constructions. Their mastery of complex construction depends on the extent to which these are used by both parents and teachers (Huttenlocher 2002). Thus, the learning of language relies not only on innateness but also on the environment, represented by families, teachers, media and other cultural inputs. Indeed, recent developments in neuroscience are highlighting how environment can have an effect on brain development itself.

\section{The plastic brain}

Plasticity is an intrinsic property of the brain, allowing the nervous system 'to escape the restriction of its own genome and thus adapt to environmental pressures, physiological changes and experiences' (Pascual-Leone 2005). Over the past few decades it has become clear that the anatomy of the brain is influenced by the physiology of the body, by emotions and cognitions (Damasio 1994) and also by environmental stimuli (Trevarthen 2001). It is through this plasticity of the brain that we can see that executive functions are systematically linked to language acquisition. Research conducted on theory of mind has shed light on this important relationship (Hauser 2008). Lohman \& Tomasello (2003) describe how 3-yearold children improve their theory of mind through the appropriate use of language skills. This supports a large study conducted by Slomkowski \& Dunn, who observed that 40-month-old toddlers display differing abilities in understanding others' feelings and 'reading' others' minds based on their differing levels of verbal ability and articulateness (Slomkowski 1996).

\section{Executive functions}

The executive system of the brain is involved in a number of psychiatric disorders seen in children and young people, including intellectual disability (Siegal 1989), ADHD (Pratt 2000) and Tourette syndrome (Singer 1991). It has therefore become a focus for neuropsychologists and researchers in the field of child development. Executive functions are cognitive abilities that control and regulate other abilities and behaviours and they are needed for planning ahead, goal-directed behaviours, abstract thinking, inhibiting actions and forming new concepts. They are mostly localised in the frontal area of the brain. The dorsolateral prefrontal area has been specifically identified with executive functions and working memory (MacPherson 2002). Executive functions allow us to organise our behaviour temporally and to override immediate demands in favour of longer-term goals (Dawson 2004). This skill requires self-control and it develops as the brain matures. Studies illustrate how infants' and children's cognitive achievements seem to depend on the development of the prefrontal cortex (Posner 1998). Hence, self-regulatory skills, for both attention and emotions, appear to begin in infancy (Haith 1988) and continue into late adolescence (Steinberg 2003). Self-regulation of attention develops particularly rapidly between 2 and 7 years of age (Rothbard 2003). The prefrontal cortex does not complete its development until early adulthood (Giedd 2004).

The human prefrontal cortex is the brain structure exposed the longest to the shaping influence of the environment and so the environment will have a major influence on an individual's developmental pathway.

In summary, poor executive functions lead to psychiatric problems and poor language acquisition has a negative impact on executive functions. There is therefore a potential link between the quality of language acquisition and some mental health difficulties in childhood.

\section{Essential and intermediary functions of language}

It is essential to differentiate between functions for which language development is crucial and those for which language has only a mediating effect (Box 5). Functions such as communication, 
BOX 5 The role of language

Language is crucial in:

- communication

- meaning-making and the sharing of experience

- hypothesis articulation

- thought abstraction

- emotion labelling and identification

Language has only a mediating effect in:

- attachment

- emotional attunement with carers

- intersubjective relationships

meaning-making and sharing of experience, hypothesis articulation, abstract thinking, emotion labelling and identification are not possible without language. Attachment, emotional attunement with carers and intersubjective relationships (Trevarthen 1993) all occur independently of language but are mediated by it.

Parental attunement with the child, which depends on the parent's personality and external family circumstances, enables effective learning from an early age and supports the child in developing their knowledge of emotions. A small study of very young deaf children (under 3 years of age) from hearing families showed how parental interaction affects the child's learning of language regardless of the type of language used (spoken or signed): the most effective approach was one of encouraging the child to participate, through a more child-centred interaction (Janjua 2002).

We can take this beyond the process of language acquisition, highlighting the importance of nonlanguage-mediated mother-and-baby interactions, which are negatively affected by compromised communication.

Humans are born with the innate abilities to share intention with others and to discern other's intentions (Tomasello 2008); they are also born with the ability to communicate and to imitate from very early age (Meltzoff 1977). This is why communication between mother (or primary carer) and baby starts well before the child is able to produce words or sentences. It starts with protoconversation. During this time, communicating with each other using sounds, 'motherese' and facial expressions, mother and baby learn to share their actions and emotions through a process of synchronisation and attunement that allows the child to progressively develop the ability to understand the emotional states of others. If it is not known that the child has impaired hearing, this process is obviously compromised.
Studies have shown a different pattern of interaction between deaf children and hearing mothers compared with hearing children and hearing mothers. Although deafness does not prevent the development of a healthy attachment between a hearing mother and a deaf child, these dyads tend to spend significantly less time interacting, the mother initiates interaction more frequently but the child tends to terminate such interaction sooner (Lederberg 1990). This may be because there is a lack of attunement. In clinical practice, mothers have often stated their preoccupation with their child's sensory impairment, which could distract them from the child's non-linguistic cues, causing the intersubjective rhythm to be lost. Hence, the interaction between a hearing mother and a deaf child is more susceptible to poorer emotional regulation, linked to the mother's potential growing sense of incompetence at communication and inability to tune in to the child in a 'deafaware' manner.

\section{Language and emotional regulation}

The intricate way in which language development has an impact on brain development is now clearer. It affects both the brain and the developing child's sense of self. Lack of language will reduce possible interactions with hearing carers. This will affect the child's attachment style and the parent's ability to 'tune in' to their child. Concurrently, lack of effective communication will prevent the developing deaf child from elaborating, through abstract thinking, events that occur in their life. This in turn will stop the child integrating the experience of those events into their developing sense of self. At the same time, the developing executive system will be affected: the child will progressively become more unable to control their actions, have great difficulty in learning to think abstractly, be unable to adjust to new situations and be less able to understand others' points of view and mental states, or will tend to develop this ability much later than hearing peers. This will lead to a greater tendency to develop emotional and behavioural difficulties, for instance being more likely to 'explode' or show ADHD-like symptoms. Furthermore, these difficulties may not be well managed by the parents when they first occur, because of problems with communication and a tendency to make more allowance for the 'disabled' child.

Of course, the degree to which all of this occurs varies depending not only on the degree of interaction with the parents but also on life circumstances (e.g. abuse of the child or illness of another family member), parental education, the information received at the time of diagnosis and the support provided by local services. 


\section{Language and theory of mind}

Autism-spectrum disorders are neurodevelopmental disorders characterised by repetitive behaviour, delays in language development and difficulties in social communication. Research indicates that genes are a significant causative factor in these disorders (Rutter 2000), but the picture is complex, with multiple candidate genes implicated (Risch 1999).

\section{Difficulties of diagnosis}

Deafness and autism-spectrum disorders both have a considerable impact on communication and, when concurrent, are liable to have a cumulative effect. The combination of their features may confuse the diagnostic picture, resulting in early misdiagnosis and inappropriate treatment, or diagnostic overshadowing and subsequent delays in recognition and intervention. Although deaf children with autism-spectrum disorders demonstrate the same symptomatology as similarly diagnosed hearing children (Roper 2003) deaf children have been found to be diagnosed on average 12 months later than their hearing peers (Mandel 2005). The lack of diagnostic tools for assessment of autism-spectrum disorders in deaf children has been posited as a contributory factor (Szymanski 2008).

Our clinical experience points to the potential for false-positive diagnosis by people unaccustomed to working with deaf children: in an environment with limited access to language, deaf children are liable to have impaired communication strategies and may show a strong preference for predictability, routine and inflexibility that has the appearance of stereotyped behaviour (which resolves when successful communication strategies are employed). Children in a mainstream setting who appear isolated from hearing peers and relate better to the adults around them providing communication support may present differently in the company of age-appropriate deaf peers. Our clinical observations have indicated that the increasing use of cochlear implantation has resulted in a growing awareness of the higher incidence of specific language disorders in deaf children which, in combination with other factors, may present similarly to autism-spectrum disorders.

\section{Theory of mind}

Just as children with autism-spectrum disorders are significantly delayed in their development of theory of mind (Baron-Cohen 1985), so are deaf children of hearing parents (de Villiers 2000). This delay may further contribute to diagnostic uncertainty. It has been attributed to the children's restricted exposure to and participation in talk about the mind - mental state discourse (Peterson 2000) - and is irrespective of communication modality (Peterson 2004). In contrast, the theory of mind performance of deaf children of deaf parents equates to that of their hearing peers (Schick 2007), supporting the view that the delay relates to deficits in communicative experience. Mothers' mental state discourses have been related to their deaf children's theory of mind skills and strongly correlated with the mothers' greater proficiency at signing. The effect of this maternal discourse remained significant even when the deaf children started school (Moeller 2006). Consequently, poor theory of mind is not a reliable indicator of autismspectrum disorders in deaf children.

\section{Diagnostic markers}

So what are the reliable diagnostic clues? Box 6 lists a number of 'red flags' (Szymanski 2008) and indicators (Edwards 2008) of autism-spectrum disorders in children who are deaf.

An interesting finding is that even where correct diagnoses of autism-spectrum disorders have been made, communication within the family unit may have an influence on the perception of the symptomatology and, consequently, the focus of therapy. This is evidenced by a small study which found that hearing parents of deaf children with autism-spectrum disorders reported difficulties in the areas of socialisation, communication and behaviour (e.g. repetitive or self-injurious behaviour), whereas deaf parents reported that socialisation problems were the most problematic factors (Szymanski 2008).

However, outcome research into effective interventions has been shown to have limitations

\section{B0X 6 Clues to autism-spectrum disorders in deaf children}

Red flags
- Poor eye contact
- Difficulty imitating facial expression
- Difficulty engaging in shared attention (looking in same
direction as caregiver)
- Inflexibility to clearly communicated changes in routine
- Obsessional interests
Diagnostic indicators
- The absence of communicative intent
- The absence of joint attention skills
- The presence of behavioural disturbance suggestive of
disorder rather than simply delay

(Edwards 2008; Szymanski 2008) 
(Diggle 2007) and the development of effective interventions for deaf children with autismspectrum disorders is still work in progress.

\section{Conclusions}

Children with severe hearing impairment are at greater risk of developing psychiatric disorders and of poor psychosocial adjustment compared with their hearing peers. The reason for this is the barrier to efficient language acquisition. It is therefore essential to minimise the damage that lack of language or delayed language development can cause and this can be achieved through two strategies.

First, services must ensure early diagnosis of hearing impairment, followed by provision of the right information to parents on the use of language. This is the aim of the National Health Service's newborn hearing screening programmes in the four countries of the UK. At a very specific level, for instance, it has been suggested that children with autism-spectrum disorders have auditory processing deficits and may struggle with conversion of auditory information to vocal utterances (Bonvillian 1981). However, the incorporation of facial expression and gesture into signing can help communication (Chamberlain 2000) and it is important for the hearing parent to be aware of this at diagnosis.

Facilitating better interaction between parents and their deaf child minimises the possibility that the child will develop an attachment disorder or emotional dysregulation. This is achieved through post-diagnosis counselling for parents and through helping parents to use communication strategies focused on the child's specific needs. It is important to ensure that the child is fully integrated into a school that is aware of and respects the child's communication needs.

Second, if necessary, families must have access to specialised child and adolescent mental health services, so that the right assessment and treatment is offered to children and young people with hearing impairment. Clinicians without experience of hearing-impaired children often misinterpret the 'signs' and wrongly diagnose and treat them. This failure has several causes: their inadequate skills in communicating with deaf children; their lack of knowledge of the complex factors implicated in the development of psychiatric problems in this group; and the paucity of tools validated for the use with deaf children and young people.

Symptoms seen in ADHD are common to a number of disorders (such as anxiety, oppositional defiant disorder, reactive attachment disorder, and communication/language disorders) and we have discussed how deaf children from hearing families are more vulnerable to these. Lack of language can also mimic some of the symptoms of an autismspectrum disorder, such as lack of empathy, echolalia and isolation. Hence, assessing a deaf child with emotional/behavioural difficulties can be a complex task, as a painstaking unpicking of variables is needed to ensure a correct diagnosis and an effective treatment plan. This may be achieved by offering a careful, multidisciplinary assessment by skilled, specially trained professionals. Assessors should be supported by sign language interpreters with training and experience in child mental health and developmental psychology.

\section{References}

Baron-Cohen S, Leslie AM, Frith U (1985) Does the autistic child have theory of mind? Cognition 21: 37-46.

Bonvillian JD, Nelson KE, Rhyne JM (1981) Sign language and autism. Journal of Autism and Developmental Disorders 11: 125-37.

Bruner J (1983) Child's Talk: Learning to Use Language. Norton.

Chamberlain C, Mayberry RI (2000) Theorising about the relationship between American Sign Language and reading. In Language Acquisition by Eye (eds C Chamberlain, JP Morford, RII Mayberry): 251-9. Erlbaum.

Damasio AR (1994) Descartes' Error: Emotion, Reason and the Human Brain. Grosset/Putnam.

Dapretto M (2006) Understanding emotions in others: mirror neuron dysfunction in children with autism spectrum disorders. Nature Neuroscience 9: 28-30.

Dawson P, Guare R (2004) Executive Skills in Children and Adolescents: A Practical Guide to Assessment and Intervention. Guilford Press.

de Villiers PA, de Villiers JG (2000) Linguistic determinism and the understanding of false beliefs. In Children's Reasoning and the Mind (eds P Miltchell, K Riggs): 189-226. Psychology Press.

Diggle T, McConachie HR, Randle VRL (2007) Parent medicated early intervention for young children with autistic spectrum disorder. Cochrane Database of Systematic Reviews issue 2: CD003496.

du Feu M, Fergusson K (2003) Sensory impairment and mental health. Advances in Psychiatric Treatment 9: 95-103.

Dunn J (2004) Children's Friendships. The Beginning of Intimacy. Blackwell Publishing.

Edwards L, Crocker S (2008) Psychological Processes in Deaf Children with Complex Needs. Jessica Kingsley.

Gallaudet Research Institute (2007) Regional and National Summary of Report Data from the 2006-2007 Annual Survey of Deaf and Hard of Hearing Children and Youth. Gallaudet University.

Giedd JN (2004) Structural magnetic resonance imaging of the adolescent brain. Annals of the New York Academy of Science 1021: 77-85.

Haith MM, Hazen C, Goodman GS (1988) Expectation and anticipation of dynamic visual events by 3.5 months-old babies. Child Development 59: 467-79.

Hauser PC, Wills KE, Isquith PK (2006) Hard-of-hearing, deafness and being deaf. In Treating Neurodevelopmental Disabilities: Clinical Research and Practice (eds JE Farmer, J Donders, S Warschausky): 119-31. Guilford Press.

Hauser PC, Lukomski J, Hillman T (2008) Development of deaf and hard of hearing students' executive function. In Deaf Cognition: Foundations and Outcomes (eds M Marschark, PC Hauser): 286-308. Oxford University Press

Hindley PA, Hill PD, McGuigan S, et al (1994) Psychiatric disorder in deaf and hearing impaired children and young people: a prevalence study. Journal of Child Psychology and Psychiatry 35: 917-34. 
Hindley PA (1997) Psychiatric aspects of hearing impairment. Journal of Child Psychology and Psychiatry 38: 101-17.

Hindley PA, Kroll L (1998) Theoretical and epidemiological aspects of attention deficit and overactivity in deaf children. Journal of Deaf Studies and Deaf Education 3: 64-72.

Hindley PA (2005) Mental health problems in deaf children. Current Paediatrics 15: 114-9.

Huttenlocher J, Vasilyeva M, Cymerman E, et al (2002) Language input and child syntax. Cognitive Psychology 45: 337-74

Janjua F, Woll B, Kyle J (2002) Effects of parental style of interaction on language development in very young severe and profound deaf children. International Journal of Paediatric Otorhinolaryngology 64: 193-205.

Jure R, Rapin I, Tuchman RF (1991) Hearing impaired autistic children. Developmental Medicine and Child Neurology 33: 1062-72.

Lederberg AR, Mobley CE (1990) The effect of hearing impairment on the quality of attachment and mother-toddler interaction. Child Development 61: 1596-604.

LeDoux JE, Phelps EA (2005) Contribution of the amygdala to emotion processing: from animal model to human behaviour. Neuron 48: 17587.

Lieberman MD, Hariri A, Jarcho JJ, et al (2005) An fMRI investigation of race-related amygdala activity in African-American and CaucasianAmerican individuals. Nature Neuroscience 8: 720-2.

Lieberman MD, Eisenberger NI, Crockett MJ, et al (2007) Putting feelings into words. Affect labeling disrupts amygdala activity in response to affective stimuli. Psychological Science 18: 421-8.

Lohman H, Tomasello M (2003) The role of language in the development of false belief understanding: a training study. Child Development 74 : $1130-44$

MacMillan HL, Fleming JE, Streiner DL, et al (2001) Childhood abuse and lifetime psychopathology in a community sample. American Journal of Psychiatry 158: 1878-83.

MacPherson SE, Phillips L, Della Sala S (2002) Age, executive function and social decision making: a dorsolateral prefrontal theory of cognitive aging. Psychology and Aging 17: 598-609.

Mandel D, Novak M, Zubritsky C (2005) Factors associated with age of diagnosis among children with autism spectrum disorders. Paediatrics 116: $1480-6$

Meins E, Fernyhough C (1999) Linguistic acquisitional style and mentalising development: the role of maternal mind-mindedness. Cognitive Development 14: 363-80.

Meltzoff AN, Moore MK (1977) Imitation of facial and manual gestures by human neonates. Science 198: 75-8.

Merleau-Ponty M (1945) Phénoménologie de la Perception. Reprinted (1962) as Phenomenology of Perception (trans C Smith) by Humanities Press.

Milad MR, Quirk GJ (2002) Neurons in medial prefrontal cortex signal memory for fear extinction. Nature 420: 70-4.

Mitchell RE, Karchmer MA (2004) Chasing the mythical ten percent: parental hearing status of deaf and hard of hearing students in the United States. Sign Language Studies 4: 138-63.

Moeller P, Schick B (2006) Relations between maternal input and theory of mind understanding in deaf children. Child Development 77: 751-66.

Moores DF (1987) Educating the Deaf: Psychology, Principles and Practices (3rd edn). Houghton Mifflin.

Nelson K (1977) Facilitating children's syntax acquisition. Developmental Psychology 13: 101-7

Nomura M, lidaka T, Kakehi K, et al (2003) Frontal lobe networks for effective processing of ambiguously expressed emotions in humans. Neuroscience Letters 348: 113-6.

Pascual-Leone A, Amedi A, Fregni F, et al (2005) The plastic human brain cortex. Annual Review of Neuroscience 28: 377-401.

Peterson CC, Siegal M (2000) Insights into theory of mind from deafness and autism. Mind and Language 15: 123-45.
Peterson CC (2004) Theory of mind development in oral deaf children with cochlear implants or conventional hearing aids. Journal of Child Psychology and Psychiatry 45: 1096-106.

Pollak SD, Tolley-Schell SA (2003) Selective attention to facial emotion to physically abused children. Journal of Abnormal Psychology 112 : 323-38.

Posner M, Rothbart MK (1998) Attention, self-regulation and consciousness. Transactions of the Philosophical Society of London B 353: 1915-27.

Pratt B, Campbell-LaVoie F, Isquith PK, et al (2000) The comparative development of executive function in elementary school with reading disorder and attention-deficit/hyperactivity disorder. Journal of the International Neuropsychological Society 6: 127.

Risch N, Spiker D, Lotspeich L, et al (1999) A genomic screen of autism evidence for a multilocus aetiology. American Journal of Human Genetics 65: 493-507.

Rizzolatti G, Fadiga L, Gallese V, et al (1996) Premotor cortex and recognition of motor actions. Cognitive Brain Research 3: 131-41.

Rizzolatti G, Craighero L (2004) "The mirror-neuron system". Annual Review of Neuroscience 27: 169-92.

Rizzolatti G, Sinigaglia C (2006) So quel che fai, Il cervello che agisce e i neuroni specchio. Raffaello Cortina Editore.

Roberts C, Hindley PA (1999) Practitioner review: the assessment and treatment of deaf children with psychiatric disorders. Journal of Child Psychology and Psychiatry 40: 151-67.

Roper L, Arnold P, Monteiro B (2003) Co-occurrence of autism and deafness. Autism 7: 245-53.

Rosenhall U, Nordin V, Sandstrom M, et al (1999) Autism and hearing loss. Journal of Autism and Developmental Disorders 29: 349-57.

Rosenkranz JA, Moore H, Grace AA (2003) The prefrontal cortex regulates lateral amygdala neuronal plasticity and responses to previously conditioned stimuli. Journal of Neuroscience 23: 11054-64.

Rothbard MK, Ellis LK, Rueda MR, et al (2003) Developing mechanisms of temperamental effortful control. Journal of Personality 71: 111343.

Rutter M (2000) Genetic studies of autism: from the 1970s into the millennium. Journal of Abnormal Child Psychology 28: 3-14.

Scheff, T (2006) Goffman Unbound! A New Paradigm for Social Science (The Sociological Imagination). Paradigm Publishers.

Schick B, de Villiers P, de Villiers J, et al (2007) Language and theory of mind: a study of deaf children. Child Development 78: 376-96.

Siegal LS, Ryan EB (1989) The development of working memory in normally achieving and subtypes of learning disabled children. Child Development 60: 973-80.

Singer HS, Walkup JT (1991) Tourette syndrome and other tic disorders. Medicine 70: 15-32

Sinkkonen J (1994) Hearing impairment, communication and personality development (PhD thesis). Department of Child Psychiatry, University of Helsinki (cited in Hindley PA (1997) Psychiatric aspects of hearing impairment. Journal of Child Psychology and Psychiatry 34: 101-17).

Slomkowski C, Dunn J (1996) Young children's understanding of other people's beliefs and feelings and their connected communication with friends. Developmental Psychology 32: 442-7.

Steel KP, Bussoli TJ (1999) Deafness genes: expressions of surprise. Trends in Genetics 15: 207-11.

Steinberg L, Scott E (2003) Less guilty by reason of adolescence. American Psychologist 58: 1009-18.

Sullivan PM, Brookhouser PE, Scanlan JM, et al (1991) Patterns of physical and sexual abuse of communicatively handicapped children. Annals of Otology, Rhinology and Laryngology 200: 188-94.

Szymanski C, Brice PJ (2008) When autism and deafness coexist in deaf children. Odyssey: New Directions in Deaf Education 9: 10-15.

Tidmarsh L, Volkmar FR (2003) Diagnosis and epidemiology of autism spectrum disorders. Canadian Journal of Psychiatry 48: 517-25.
MCO answers

$1 \mathrm{c} \quad 2 \mathrm{~d} \quad 3 \mathrm{c} \quad 4$ e $5 \mathrm{c}$ 
Tomasello M (1999) The Cultural Origin of Human Cognition. Harvard University Press.

Tomasello M (2000) Culture and cognitive development. Current Directions in Psychological Science 9: 37-40.

Tomasello M (2008) Origins of Human Communication. MIT Press.

Trevarthen C (1979) Communication and cooperation in early infancy: a description of primary intersubjectivity. In Before Speech (ed M Bullowa). Cambridge University Press.

Trevarthen C (1993) The self born in intersubjectivity: the psychology of an infant communicating. In The Perceived Self: Ecological and Interpersonal Sources of Self-Knowledge (ed U Neisser): 121-73. Cambridge University Press.

Trevarthen C, Aitken K (2001) Infant intersubjectivity: research, theory and clinical applications. Journal of Child Psychology and Psychiatry 42: 3-48.

Vaccari C, Marschark M (1997) Communication between parents and deaf children: implications for socio-emotional development. Journal of Child Psychology and Psychiatry 38: 793-801.
Van Eldik T, Treffers PDA, Veerman JW, et al (2004) Mental health problems of deaf Dutch children as indicated by parents' responses to the Child Behaviour Checklist. American Annals of the Deaf 148: 390-4.

Vostanis P, Hayes M, Du Feu M, et al (1997) Detection of behavioural and emotional problems in deaf children and adolescents: comparison of two rating scales. Child: Care, Health and Development 23: 233-46.

Vygotsky L (1978) Mind in Society: The Development of Higher Psychological Processes. Harvard University Press.

Wills L, Wills K (2005) Hearing impairment. In Developmental and Behavioral Pediatrics: A Handbook for Primary Care leds S Parker, B Zuckerman, M Augustyn): 215-21. Lippincott Williams \& Wilkins.

Woll B (2008) Mental Capital and Wellbeing: Making the Most of Ourselves in the 21st Century. State-of-Science Review: SR-D5 Deafness and Hearing Impairment. Foresight, UK Government Office for Science.

Yoshinaga-Itano C (2000) Successful outcomes for deaf and hard-ofhearing children. Seminars in Hearing 21: 309-25.

\begin{tabular}{|c|c|c|}
\hline MCQs & d impaired communication & c the child does not turn when called by name \\
\hline Select the single best option for each question stem & e idiopathic conditions. & $\mathrm{d}$ inflexible patterns of behaviour \\
\hline $\begin{array}{l}1 \text { What percentage of deaf children are born } \\
\text { to deaf parents? } \\
\text { a } 90 \% \\
\text { b } 20 \% \\
\text { c } 5 \% \\
\text { d } 95 \% \\
\text { e } 45 \% \text {. } \\
2 \text { What is the most significant contributory } \\
\text { factor to the additional mental heath needs } \\
\text { of deaf children? } \\
\text { a genetic factors } \\
\text { b infective agents } \\
\text { c prematurity }\end{array}$ & $\begin{array}{l}3 \text { How does the incidence of mental health } \\
\text { problems in deaf children compare to their } \\
\text { hearing peers? } \\
\text { a half } \\
\text { b same incidence } \\
\text { c double } \\
\text { d } 10 \% \text { higher } \\
\text { e ten times higher. } \\
4 \text { Which is a reliable indicator for making a } \\
\text { diagnosis of autism-spectrum disorders in } \\
\text { deaf children? } \\
\text { a delay in acquisition of speech } \\
\text { b delay in developing theory of mind }\end{array}$ & $\begin{array}{l}5 \text { Which of the functions below occur } \\
\text { independently of language? } \\
\text { a hypothesis articulation } \\
\text { b emotional labelling } \\
\text { c attachment } \\
\text { d thought abstraction } \\
\text { e meaning making. }\end{array}$ \\
\hline
\end{tabular}

